\title{
Cytoplasmic volume of recipient oocytes affects the nucleus reprogramming and the developmental competence of HMC buffalo (Bubalus bubalis) embryos
}

\author{
Xiaohua LIU1)\#, Chan LUO'1)\#, Kai DENG ${ }^{1) \#, ~ Z h u l i a n ~ W U 1), ~ Y i n g m i n g ~ W E I ~}{ }^{1)}$, \\ Jianrong JIANG ${ }^{1)}$, Fenghua $\mathrm{LU}^{1) *}$ and Deshun $\mathrm{SHI}^{1}{ }^{1) *}$ \\ 1)Guangxi High Education Key Laboratory for Animal Reproduction and Biotechnology, State Key Laboratory \\ for Conservation and Utilization of Subtropical Agro-Bioresources, Guangxi University, Nanning 530005, \\ China
}

J. Vet. Med. Sci.

80(8): 1291-1300, 2018

doi: 10.1292/jvms.18-0043

Received: 30 January 2018 Accepted: 7 June 2018

Published online in J-STAGE:

20 June 2018
ABSTRACT. The present study was undertaken to examine the effects of cytoplasmic volume on nucleus reprogramming and developmental competence of buffalo handmade cloning (HMC) embryos. We found that both HMC embryos derived from $\sim 150 \%$ cytoplasm or $\sim 225 \%$ cytoplasm resulted in a higher blastocyst rate and total cell number of blastocyst in comparison with those from $\sim 75 \%$ cytoplasm $(25.4 \pm 2.0,27.9 \pm 1.6 \%$ vs. $17.9 \pm 3.1 \% ; 150 \pm 10,169 \pm 12$ vs. 85 $\pm 6, P<0.05$ ). Meanwhile, the proportions of nuclear envelope breakdown (NEBD) and premature chromosome condensation (PCC) were also increased in the embryos derived from $\sim 150$ or $\sim 225 \%$ enucleated cytoplasm compared to those from $\sim 75 \%$ cytoplasm. Moreover, HMC embryos derived from $\sim 225 \%$ cytoplasm showed a decrease of global DNA methylation from the 2-cell to the 4 -cell stage in comparison with those of $\sim 75 \%$ cytoplasm $(P<0.05)$. Furthermore, the expression of embryonic genome activation (EGA) relative genes (eIF1A and U2AF) in HMC embryos derived from $\sim 225 \%$ cytoplasm at the 8 -cell stages was also found to be enhanced compared with that of the $\sim 75 \%$ cytoplasm. Two of seven recipients were confirmed to be pregnant following transfer of blastocysts derived from $\sim 225 \%$ cytoplasm, and one healthy cloned calf was delivered at the end of the gestation period, whereas no recipients were pregnant after the transfer of blastocysts derived from $\sim 75 \%$ cytoplasm. These results indicate that the cytoplasmic volume of recipient oocytes affects donor nucleus reprogramming, and then further accounted for the developmental ability of the reconstructed embryos.

KEY WORDS: buffalo, cytoplasmic volume, embryo developmental competence, handmade cloning

Somatic cell nuclear transfer (SCNT) is the most efficient and viable technique to propagate highly valued endangered and extinct domestic animals [15]. Following the birth of first cloned sheep, "Dolly", numerous endangered species and elite domestic animals were generated by SCNT via micromanipulation-based enucleation and nuclear transfer. More than $99 \%$ of embryos or offspring dealing with SCNT that have been reported were produced via a micromanipulation-based approach [37]. However, the complicated micromanipulation procedure and expensive micromanipulators hamper the advancement of SCNT in domestic animals. Thus, one of the major necessities in traditional cloning was to reduce the costs without compromising with the efficiency [39]. Handmade cloning (HMC) is an advanced procedure of enucleation of zona-free mammalian oocytes by hand bisection that is based on SCNT and was first reported by Vajta et al. in 2001 [38]. The requirement of expensive micromanipulators and skilled expertise was eliminated in the HMC technique, proving that it was a major revolution in the field of embryology [42]. With the improvement in the enucleation of zona-free oocytes [17, 32, 33] and the culture system [1, 36, 40], HMC, as a more efficient and economical technique in comparison to the micromanipulator-based approach, was successfully used to produce cloned offspring in several livestock species such as cattle [22], buffalo [11], sheep [50], pigs [9] and horses [14]. Although HMC has achieved certain success and offers a new route for SCNT, the problems that restrict the success of traditional SCNT, including incomplete nucleus reprogramming, chromosome remodeling failure, embryonic genomic activation delay, and lower in vivo developmental competence, still need to be resolved.

*Correspondence to: Shi, D. S.: ardshi@163.com, Lu, F. H.: Ifhgggg@163.com

\#These authors contributed equally to this work.

O2018 The Japanese Society of Veterinary Science

This is an open-access article distributed under the terms of the Creative Commons Attribution Non-Commercial No Derivatives (by-nc-nd) License. (CC-BY-NC-ND 4.0: https://creativecommons.org/licenses/by-nc-nd/4.o/) 
In normally fertilized embryos, the epigenetic modification pattern of sperm and oocyte nucleus can be reprogrammed to a totipotent state by oocyte cytoplasm. In order to have successful reprogramming in SCNT, the donor cells should be completely erased to switch off the expression of tissue-specific gene and reprogrammed to switch on gene expression in embryos [21]. The quality and quantity of reprogramming factors in the oocyte cytoplasm are considered to be the deciding factors of the overall reprogramming efficiency in SCNT [23]. Previous reports showed that the blastocyst development rate and the total number of blastomeres decreased remarkably in micromanipulation-based cloned embryos when the cytoplasmic volume of the recipient oocyte was sufficiently reduced $[12,49]$. Compared to the process of in vitro fertilization (IVF), both micromanipulator-assisted and HMC enucleation resulted decrease in cytoplasm volume, which is considered to contain reprogramming factors. While micromanipulator-assisted enucleation results in the removal of 5-50\% of the cytoplasm [44], HMC also results in almost a $15-50 \%$ loss of cytoplasmic volume [23]. Therefore, increasing the cytoplasmic volume should be an effective way to improve the efficiency of HMC embryo development, and accumulated data have proven that it is feasible. It had been reported that increasing cytoplasmic volume either by fusion or aggregation, had a positive effect on the in vitro development of HMC embryos and the establishment of pregnancies $[23,26]$. However, there is little information available that is related to the mechanism of how cytoplasmic volume can affect the developmental capacity of HMC embryos. Therefore, further investigation is required to explore the molecular mechanism of recipient oocyte cytoplasm and its association with nucleus reprogramming and embryonic development.

Buffalo (Bubalus bubalis) is an important domestic animal that inhabits the tropical and subtropical region, and is characterized with a high content of fat and protein in milk. However, the milk yield of Chinese swamp buffalos is extremely low (normally less than $1,000 \mathrm{~kg}$ /year) so it is in urgent need of improvement. The cloning of buffalos through nuclear transfer is a potential alternative approach in the genetic improvement of buffalos [29]. Nowadays, HMC is a simple and inexpensive technique that is preferred over micromanipulation-based SCNT [35]. Previous studies have proven that the in vitro developmental potential of HMC embryos is equal to those produced through traditional SCNT. However, very few HMC buffalos have been reported $[11,23,27]$, so the in vivo developmental potential of HMC embryos still needs to be evaluated.

Precise nucleus reprogramming of somatic cells is a prerequisite for the success of somatic cell nuclear transfer [23]. The quantity and quality of the cytoplasm play an important role in the process of nuclear reprogramming. It has been reported that the development of bovine [31], porcine [5], and ovine [25] SCNT embryos can be improved by treating donor cells with oocytes extracts. This evidence suggested that reprogramming factors in cytoplasm determine the overall reprogramming efficiency. Recently, accumulated data proved that HMC embryo development can be enhanced by increasing the cytoplasmic volume of reconstructed embryos [4, 23, 26]. The developmental potential of cloned embryos has been related to nucleus remodeling, epigenetic reprogramming, and embryonic genome activation. Up to now, the effects of cytoplasmic volume on the in vivo development of HMC embryos, important events involving nucleus remodeling, DNA methylation, and embryonic genome activation (EGA) of HMC embryos were still unclear.

The present study was undertaken to investigate the molecular mechanism of recipient oocyte cytoplasm and its association with the nucleus reprogramming and success of embryo development. The in vitro developmental competence of handmade cloned buffalo embryos; the molecular mechanism including the remodeling pattern of donor nucleus in reconstructed embryo; global DNA methylation of HMC embryos from the 2-cell stage to blastocyst; and the status of EGA; were examined. Finally, the in vivo developmental competence of the HMC embryos derived from $\sim 75 \%$ cytoplasm and $\sim 225 \%$ cytoplasm were evaluated.

\section{MATERIALS AND METHODS}

\section{Ethics statements}

This study was carried out in accordance with the guidelines for the care and use of animals of Guangxi University. All of the experiments and protocols were performed in strict accordance with the Guide for Care and Use of Laboratory Animals and explicitly approved by the Guangxi University Committee on Animal Research and Bioethics.

\section{Reagents and media}

All of the chemicals used were purchased from Sigma Chemical Co. (St. Louis, MO, U.S.A.), with the exception of TCM 199 powder, which was purchased from Gibco BRL (Paisley, Scotland, U.K.), and fetal bovine serum (FBS) and Dulbecco's Modified Eagle's Media (DMEM), which were bought from Invitrogen Co. (Carlsbad, CA, U.S.A.). The preparation of media used in this study, including in vitro maturation (IVM) medium and embryo culture medium (CM) was described by Shi et al. [29].

\section{In vitro maturation of oocytes}

In vitro maturation of oocytes was carried out as described previously [29]. Chinese swamp buffalo ovaries were obtained from a local abattoir. Ovaries were excised within 20 to $30 \mathrm{~min}$ after slaughter and were transported to the laboratory within $4 \mathrm{hr}$ in a thermos containing PBS at 35 to $37^{\circ} \mathrm{C}$. Buffalo cumulus-oocyte complexes (COCs) were recovered via the aspiration of follicles in diameter of 2-6 mm using a $10 \mathrm{~m} l$ disposable syringe with an 18-gauge needle. COCs with multi-layers of cumulus cells were selected for IVM. Then, COCs were washed twice in the IVM medium (TCM-199 supplemented with $26.2 \mathrm{mM} \mathrm{NaHCO}_{3}, 5 \mathrm{mM}$ HEPES, $5 \%$ OCS and $0.1 \mu \mathrm{g} / \mathrm{ml} \mathrm{FSH}$ ) and cultured in a $30 \mathrm{~mm}$ glass dish containing $1.5 \mu \mathrm{lVM}$ medium for $22 \mathrm{hr}$ under a humidified atmosphere of $5 \% \mathrm{CO}_{2}$ in air at $38.5^{\circ} \mathrm{C}$. 

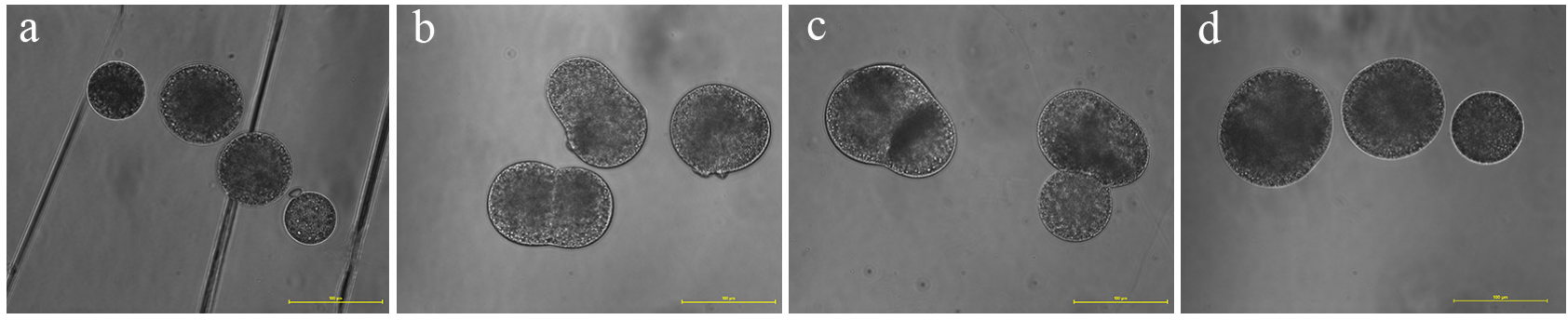

Fig. 1. Reconstruction of embryos with different cytoplasm. (a): Cytoplasm with different volume selected after bisection, (b) $\sim 150 \%$ cytoplasm fusion processes, (c) $\sim 225 \%$ cytoplasm fusion processes, and (d) embryos with different cytoplasm after fusion. Bar $=100 \mu \mathrm{m}$

\section{Production of handmade cloning embryos}

HMC was performed as described previously [23] with some modifications. In brief, oocytes with an extruded first polar body were selected for enucleation. Denuded oocytes were stripped of their zona pellucida using $2 \mathrm{mg} / \mathrm{m} l$ pronase. Then oocytes with completely digested zona pellucida were transferred to TCM199 (TCM199 medium containing 20\% FBS) and incubated at $38.5^{\circ} \mathrm{C}$ until a prominent protrusion cone was easily visible. Protrusion cone guided bisection was performed under a stereo zoom microscope (Nikon, Tokyo, Japan) using an ultra-sharp splitting blade (ESE020, Total Reproduction Pty. Ltd., Camperdown, Australia) in $50 \mu l$ TCM199 with $5 \mu \mathrm{g} / \mathrm{m} l$ cytochalasin-B. The larger enucleated cytoplasm ( $75 \%$ of the original oocyte, Fig. 1a) without a protrusion cone were transferred to TCM199 and incubated for $30 \mathrm{~min}$ to regain the spherical shape, and then immersed in Phytohemagglutinin $(0.5 \mathrm{mg} / \mathrm{m} l)$ for 5-10 sec and transferred to PVA (TCM199 with $1 \%$ polyvinyl alcohol) containing donor cells. Each enucleated cytoplasm in the PVA containing donor cells was then conjoined with a single, rounded fetal fibroblast, followed by conjoining one or two enucleated cytoplasm to the couplets. Then, the couplet was transferred to a droplet of 100 $\mu l$ fusion medium ( $0.28 \mathrm{M}$ mannitol, $0.1 \mathrm{mM} \mathrm{CaCl}_{2}, 0.1 \mathrm{mM} \mathrm{MgSO}_{4}, 5 \mathrm{mM}^{2}$ Hepes and $0.1 \% \mathrm{BSA}$ ) overlaid with mineral oil, and then placed on the micromanipulator with two platinum needle electrodes $(0.2 \mathrm{~mm}$ apart). The fusion was induced with two direct current pulses of $1 \mathrm{kv} / \mathrm{cm}$ for $10 \mu$ s using an ECM2001 Electrocell Manipulator (BTX Inc., San Diego, CA, U.S.A.). For the construction of embryos with decreased or increased cytoplasmic volume, either only one enucleated cytoplasm ( $75 \%$ cytoplasm) or couplets with two $(\sim 150 \%$ cytoplasm, Fig. 1 b) or three ( $225 \%$ cytoplasm, Fig. 1c) enucleated cytoplasm were allowed to fuse, creating a different cytoplasmic volume (Fig. 1d). Then, the couplets were incubated in the TCM199 for $30 \mathrm{~min}$ at $38.5^{\circ} \mathrm{C}$. The reconstructed embryos were activated previously [23]. Briefly, the reconstructed embryos were induced by exposure to $5 \mu \mathrm{M}$ Ionomycin in $\mathrm{CM}$ for $5 \mathrm{~min}$ and subsequent incubation in $2 \mathrm{mM}$ 6-dimethylamino-purine for $3 \mathrm{hr}$ at $38.5^{\circ} \mathrm{C}$ and $5 \% \mathrm{CO}_{2}$ in air.

\section{In vitro fertilization}

In vitro fertilization was carried out as described previously [30]. Briefly, the frozen semen straw $(0.25 \mathrm{ml} / \mathrm{straw})$ was thawed in a $37^{\circ} \mathrm{C}$ water bath. The thawed semen was layered under fertilization medium (Tyrode's medium supplemented with $10 \mathrm{mM}$ caffeine, $20 \mu \mathrm{g} / \mathrm{m} l$ heparin, and $20 \mathrm{mg} / \mathrm{ml} \mathrm{BSA}$ ) in a conical tube for the swim-up procedure. After incubation for $30 \mathrm{~min}$ at $38.5^{\circ} \mathrm{C}$, the top of the medium containing the more motile sperm was collected and centrifuged to harvest the sperm. Then, the spermatozoa pellet was resuspended in fertilization medium at a concentration of $5.0 \times 10^{6} \mathrm{sperm} / \mathrm{m} l$ for fertilization. IVM oocytes were washed twice in fertilization medium and transferred into a $30 \mu l$ droplet of fertilization medium under sterile mineral oil (20 oocytes/drop). Then, $5 \mu \mathrm{l}$ of semen was added to the droplet containing oocytes and incubated for $24 \mathrm{hr}$ at $38.5^{\circ} \mathrm{C}$ under a humidified $5 \% \mathrm{CO}_{2}$ atmosphere.

\section{In vitro culture of embryos}

The in vitro culture of IVF embryos was also performed as previously described [30]. Briefly, embryos derived from IVF were placed into co-culture with granulosa cell monolayers in a $30 \mu l$ droplet of $\mathrm{CM}$ overlaid with mineral oil under a humidified atmosphere of $5 \% \mathrm{CO}_{2}$ in air at $38.5^{\circ} \mathrm{C}$. Granulosa cell monolayers were established $48-72 \mathrm{hr}$ before the introduction of embryos. After the introduction of the embryos, half of the medium was replaced with fresh medium every $24 \mathrm{hr}$. The cleavage of the reconstructed embryos was checked on Day 2 (Day 0 was the day of IVF), and the number of developed blastocysts was recorded within eight days of co-culture.

Embryos derived from HMC were placed in a Well of the Well (WOW) system and cultured in $400 \mu l$ embryo CM under a humidified atmosphere of $5 \% \mathrm{CO}_{2}$ in air at $38.5^{\circ} \mathrm{C}$. The WOWs were prepared in a 4-well dish according to the method reported previously [40].

\section{Estrous synchronization of recipients and embryo transfer}

Estrous synchronization of recipients and embryo transfer was carried out as described previously [46]. Briefly, Non-pregnant buffalo with normal uterus were synchronized with $100 \mu \mathrm{g}$ of a GnRH analogue given at Day $0,500 \mu \mathrm{g} \mathrm{PGF}_{2} \alpha$ analogue at Day 7, and another $100 \mu \mathrm{g} \mathrm{GnRH}$ analogue at Day 9. Estrus was observed on Days 10 to 13, and blastocysts were transferred nonsurgically into the uterine horn ipsilateral to the ovary containing a palpable corpus luteum of recipient buffalos at Day 6 of estrous cycle. The pregnancy status was determined by rectal palpation 60 days after embryo transfer. 


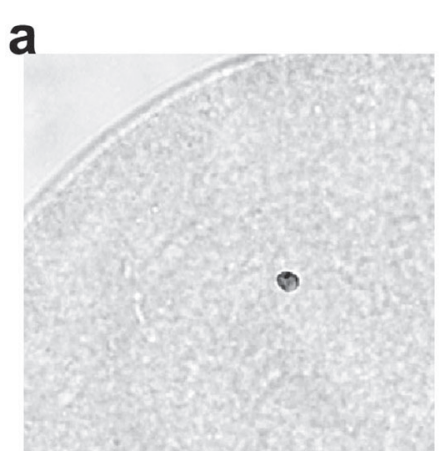

b

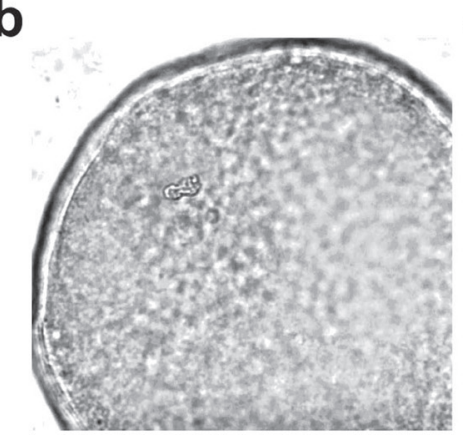

c

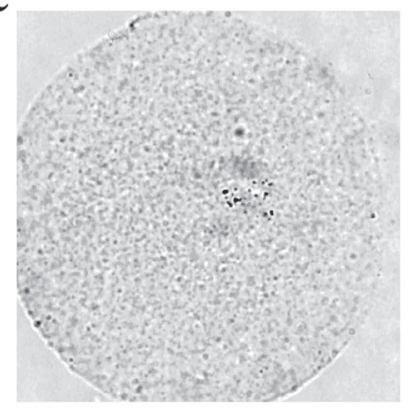

Fig. 2. The remodeling pattern of the donor nucleus in a reconstructed embryo $(\times 200)$. (a): The donor nucleus into the oocyte, (b): nuclear envelope breakdown, and (c): premature chromosome condensation.

\section{Assessment of nucleus remodeling pattern by acetic orcein staining}

The nucleus remodeling pattern of reconstructed embryos was stained and evaluated as described [2]. Briefly, reconstructed embryos derived from different cytoplasmic volumes were collected respectively at $0,1.5$ and $3 \mathrm{hr}$ post-fusion and fixed in ethanol: acetic acid (3:1, v:v) for $72 \mathrm{hr}$. Then, embryos were stained with acetoorcein (1\% orcein in $45 \%$ acetic acid) for $6 \mathrm{hr}$ and differentiated by gently running in differentiation solution ( $20 \%$ glycerol [v:v] and $20 \%$ acetic acid [v:v] in distilled water). The nucleus remodeling patterns of the reconstructed embryos were evaluated using phase-contrast microscopy and characterized as nuclear envelope breakdown (NEBD) and premature chromosome condensation (PCC) (Fig. 2).

\section{Immunohistochemistry}

The dynamic pattern of DNA methylation during HMC embryonic development was examined using immunohistochemistry. IVF embryos were used as the control group. Embryos at different developmental stages (2-cell, 4-cell, and blastocyst) were washed in PBS and fixed in 3.7\% paraformaldehyde for $30 \mathrm{~min}$ at room temperature. The fixed embryos were washed three times in phosphate-buffered solution (PBS) supplemented with $0.01 \%$ Triton X-100 and $0.3 \%$ BSA (TBP), followed by permeabilization with $1 \%$ Triton X-100 for $30 \mathrm{~min}$ at room temperature. Thereafter, the embryos were blocked by $1 \%$ BSA for $1 \mathrm{hr}$. After washing three times with TBP, the embryos were treated with $2 \mathrm{M} \mathrm{HCl}$ for $20 \mathrm{~min}$, and neutralized with Tris- $\mathrm{HCl}$ (PH-8.0) for 10 min before incubation with the primary antibody $(5-\mathrm{mC}, 1: 300$ from mouse, Abcam). All of these samples were incubated overnight at $4{ }^{\circ} \mathrm{C}$. Thereafter, the embryos were washed three times in TBP and then incubated with fluorescein isothiocyanate (FITC)conjugated second antibody (goat anti-mouse immunoglobulin G, 1:200, Millipore) for $1.5 \mathrm{hr}$ at room temperature. Samples were mounted on slides with anti-fade solution (Fluoromount-GTM, SouthernBiotech, Birmingham, AL, U.S.A.) and analyzed with a confocal laser scanning microscope (Zeiss, Heidelberg, Germany). At least 10 embryos at different development stages were checked randomly, and fluorescence intensity was measured with Image J software (NIH, Bethesda, MD, U.S.A.).

\section{Embryo collection and reverse transcription}

Five embryos at each stage were collected and treated using a Cells-to-cDNA ${ }^{\mathrm{TM}}$ II Kit (Thermo Fisher Scientific, Vilnius, Lithuania) according to the method reported previously [30]. In brief, the embryos were incubated with cell lysis II, digested with DNase I (Fermentas, Hanover, MD, U.S.A.) to remove genomic DNA, and then the DNase was inactivated with EDTA. The reverse transcription reaction system consisted of SuperScript ${ }^{\mathrm{TM}}$ II Reverse Transcriptase (Invitrogen), $4 \mu \mathrm{M}$ random primer, $10 \mathrm{mM}$ dNTPs mixture, RNase inhibitor (Takara, Dalian, China), $5 \times$ First-Strand Buffer, and dithiothreitol (DTT). The reaction mixture was incubated at $42^{\circ} \mathrm{C}$ for $60 \mathrm{~min}$ and $95^{\circ} \mathrm{C}$ for $10 \mathrm{~min}$. Finally, sterile free $\mathrm{H}_{2} \mathrm{O}$ was added to adjust the final volume of cDNA to $0.2 \mu l$ per embryo.

\section{Analysis of gene expression by quantitative real-time polymerase chain reaction}

cDNA samples from embryos were analyzed via an ABI 7500 Real-Time System (Applied Biosystems, Foster City, CA, U.S.A.), and primers were designed by the Oligo 6.0 software (Table 1). The housekeeping gene $\beta$-actin was used as the reference gene, and reaction mixture in each well included $10 \mu l$ of SYBR Premix Ex TaqTM (Takara), $0.3 \mu l$ primer (10 nM), $0.4 \mu l$ of ROX Reference Dye II $(50 \times), 1 \mu l$ of cDNA and $8.3 \mu l$ of $\mathrm{H}_{2} \mathrm{O}$ (total volume of $20 \mu l$ ). The $2^{-\Delta \Delta C t}$ method was used to calculate the expression of the target genes. All of the experiments were performed with at least three replicates.

\section{Statistical analysis}

The experiments were repeated at least three times. The HMC embryos that underwent cleavage and developed to the blastocyst stage were analyzed by one-way ANOVA least significant difference (LSD)post-hoc test using the SPSS 18.0 (IBM, Armonk, NY, U.S.A.) software. The global DNA methylation and expression profiles of the target genes between the different groups were analyzed by one-way repeated-measures analysis of variance (ANOVA). $\chi^{2}$ test was used to analyze the nucleus remodeling data. Probability values of $<0.05$ were considered to be statistically significant. 
Table 1. Details of primers used for the real-time PCR analysis

\begin{tabular}{|c|c|c|c|c|}
\hline Gene & Primer name & Sequences $\left(5^{\prime}-3^{\prime}\right)$ & Fragment size (bp) & Accession No. \\
\hline \multirow[t]{2}{*}{ eIF $1 A$} & Forward & CTCCCAAGTGGCTGAGAAAG & 163 & FJ415608.1 \\
\hline & Reverse & TCACTCTCCTCCTCGCTCTC & & \\
\hline \multirow[t]{2}{*}{$U 2 A F$} & Forward & GATGTCGAGATGCAGGAACA & 155 & FJ415609.1 \\
\hline & Reverse & TCTTCTTCACGGCGAAACTT & & \\
\hline \multirow[t]{2}{*}{$\beta$-actin } & Forward & ACCGCAAATGCTTCTAGG & 199 & NM173979.3 \\
\hline & Reverse & ATCCAACCGACTGCTGTC & & \\
\hline
\end{tabular}

Table 2. In vitro developmental competence of buffalo HMC embryos produced by distinct cytoplasmic volume

\begin{tabular}{ccccc}
\hline Cytoplasmic volume & NT embryos & Cleaved (\%) & Blastocysts developed (\%) & Blastocyst cell number \\
\hline$\sim 75 \%$ & 78 & $54(69.2 \pm 8.8)^{\mathrm{b})}$ & $14(17.9 \pm 3.1)^{\mathrm{b})}$ & $85 \pm 6^{\mathrm{b})}$ \\
$\sim 150 \%$ & 71 & $51(71.8 \pm 6.5)^{\mathrm{b})}$ & $18(25.4 \pm 2.0)^{\mathrm{a}}$ & $150 \pm 10^{\mathrm{a})}$ \\
$\sim 225 \%$ & 68 & $59(86.8 \pm 2.7)^{\mathrm{a})}$ & $19(27.9 \pm 1.6)^{\mathrm{a})}$ & $169 \pm 12^{\mathrm{a})}$ \\
\hline
\end{tabular}

Data presented were from more than three replicates. Values within brackets are presented as mean \pm standard error of the mean (SEM). a, b) Within a column, values with different superscripts are significantly different $(P<0.05)$.

Table 3. Effects of cytoplasmic volume on nuclear remodeling pattern of buffalo HMC embryos

\begin{tabular}{|c|c|c|c|c|}
\hline \multirow{2}{*}{ Cytoplasmic volume } & \multicolumn{2}{|c|}{$1.5 \mathrm{hr}$ after fusion } & \multicolumn{2}{|c|}{$3 \mathrm{hr}$ after fusion } \\
\hline & NEBD & PCC & NEBD & PCC \\
\hline$\sim 75 \%$ & $\left.18 / 51(35.3 \%)^{b}\right)$ & $6 / 51(11.8 \%)^{b)}$ & $18 / 18(100 \%)$ & $12 / 18(66.7 \%)$ \\
\hline$\sim 150 \%$ & $33 / 45(73.3 \%)^{\mathrm{a})}$ & $30 / 45(66.7 \%)^{\mathrm{a})}$ & $27 / 27(100 \%)$ & $27 / 27(100 \%)$ \\
\hline$\sim 225 \%$ & $27 / 27(100 \%)^{\mathrm{a})}$ & $27 / 27(100 \%)^{\mathrm{a})}$ & $21 / 21(100 \%)$ & $21 / 21(100 \%)$ \\
\hline
\end{tabular}

Data presented were from more than three replicates. a,b) Within a column, values with different superscripts are significantly different $(P<0.05)$.

\section{RESULTS}

\section{Effect of cytoplasmic volume on in vitro development of HMC embryos}

In order to identify whether recipient oocyte cytoplasm of HMC embryos could influence the development of cloned buffalo embryos, a single trypsinized donor cell was fused respectively with one, two, or three enucleated cytoplasm to produce HMC embryos with variable cytoplasmic volume. As shown in Table 2, reconstructed embryos with $\sim 225 \%$ cytoplasm resulted in a higher cleavage rate $(86.8 \pm 2.7 \%, P<0.05)$ compared with the other groups. In addition, when the donor cells were fused with $\sim 150$ or $\sim 225 \%$ cytoplasm, the blastocyst rates of the reconstructed embryos were increased in comparison with that of donor cells fused with $\sim 75 \%$ cytoplasm $(P<0.05)$. In particular, in the group of donor cells fused with $\sim 225 \%$ cytoplasm, the blastocyst developmental rate reached $27.9 \%$. The total cell number of blastocysts derived from $\sim 150$ or $\sim 225 \%$ cytoplasm was evidently increased compared with those developed from $\sim 75 \%$ cytoplasm $(P<0.05)$. However, no significant difference in the blastocyst rates and total cell number of blastocysts were observed between the $\sim 150 \%$ cytoplasm and $\sim 225 \%$ cytoplasm groups $(P>0.05$ ).

\section{Effect of cytoplasmic volume on nucleus remodeling pattern of HMC embryos}

According to the above results, to explore the mechanism of recipient oocyte cytoplasm-related developmental potential of the HMC embryos, the nucleus remodeling pattern of the HMC embryos derived from distinct cytoplasmic volumes at different time points $(0,1.5$, and $3 \mathrm{hr}$ post-fusion) was examined. A minimal change in donor nucleus was observed after fusing with different recipient cytoplasmic volumes (Fig. 2a). NEBD occurred (Fig. 2b), and then PCC was assembled (Fig. 2c) at 1.5-3 hr post-fusion. As shown in Table 3, with the increase of recipient cytoplasmic volume, both the proportions of NEBD and PCC were increased. The proportions of HMC embryos with $225 \%$ cytoplasm appearing NEBD and PCC was 100\% (27/27) at $1.5 \mathrm{hr}$ post-fusion, which was significantly higher than that of the cytoplasmic volume $\sim 75 \%$ group cytoplasm (100 vs. $35.3 \%$ and $100 \mathrm{vs.} 11.8 \%$, respectively). However, no significant difference in the frequency of NEBD and PCC were observed between the $\sim 150 \%$ cytoplasm and $\sim 225 \%$ cytoplasm groups ( 73.3 vs. $100 \%$ and 66.7 vs. $100 \%$, respectively). At $3 \mathrm{hr}$ post-fusion, the proportions of NEBD and PCC were increased to 100 and $66.7 \%$, respectively, in the $75 \%$ cytoplasm group, while all (100\%) of the HMC embryos from the $\sim 150$ and $\sim 225 \%$ cytoplasm group completed the process of NEBD and PCC.

\section{Effects of cytoplasmic volume on DNA methylation levels of buffalo HMC embryos}

To investigate the mechanism of recipient oocyte cytoplasm and its association with the nucleus reprogramming and 

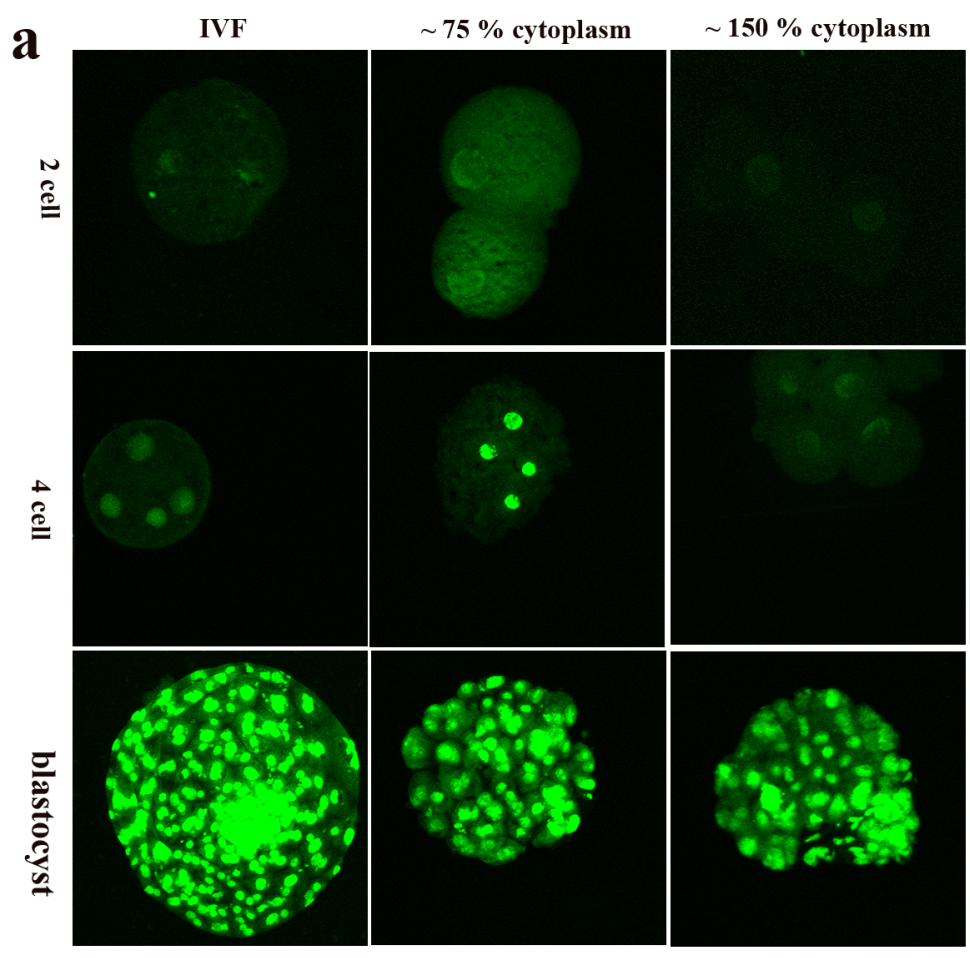

$\sim 225 \%$ cytoplasm
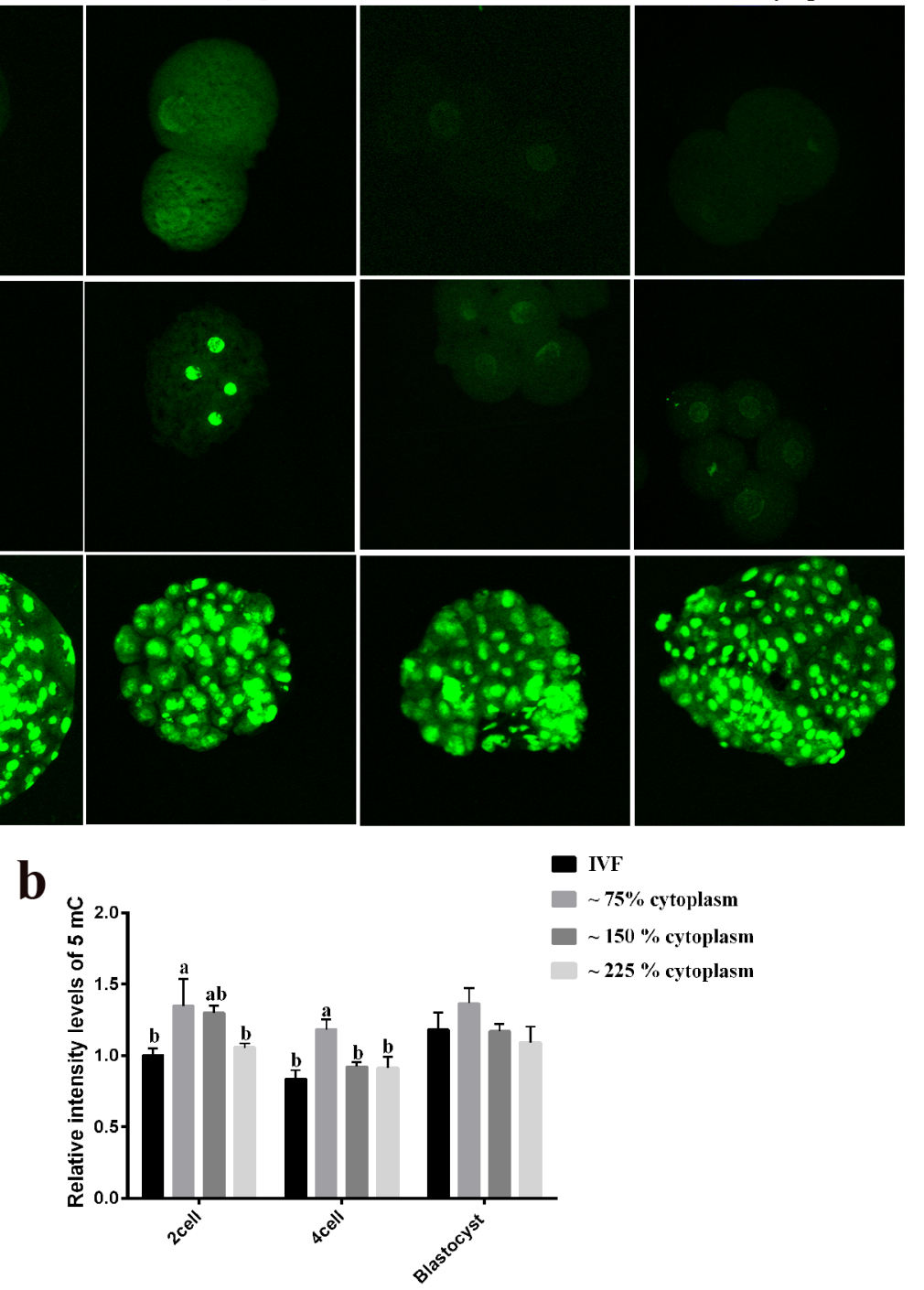

IVF

$\sim 75 \%$ cytoplasm

$\sim 150 \%$ cytoplasm

$\sim 225 \%$ cytoplasm

Fig. 3. The DNA methylation of embryos derived from IVF, $\sim 75 \%$ cytoplasm, $\sim 150 \%$ cytoplasm or $\sim 225 \%$ HMC cytoplasm embryos during preimplantation development. (a) Images of IVF, $\sim 75 \%$ cytoplasm, $\sim 150 \%$ cytoplasm or $\sim 225 \%$ cytoplasm HMC embryos stained for $5 \mathrm{mC}$ from the 2 -cell to the blastocyst stages. (b) Relative levels of $5 \mathrm{mC}$ in IVF, $\sim 75 \%$ cytoplasm, $\sim 150 \%$ cytoplasm or $\sim 225 \%$ cytoplasm HMC embryos. Each bar represents the relative fold change across the developmental stages within each embryo type. Values are presented as mean \pm SEM, and values with different superscripts $(\mathrm{a}, \mathrm{b})$ within groups are significantly different $(P<0.05)$.

developmental potential of HMC embryos, the global change of DNA methylation in HMC and IVF embryos at the 2-cell, 4-cell and blastocyst stages was measured respectively by immunostaining (Fig. 3a). In comparison with the control group, decreasing recipient oocyte cytoplasm significantly increased the methylation level of HMC embryos from the 2-cell to the 4-cell stages (Fig. 3b). Interestingly, the $\sim 225 \%$ cytoplasm embryos resulted in a decrease in the relative levels of global DNA methylation compared with that of the cytoplasmic volume $\sim 75 \%$ cytoplasm group $(P<0.05)$ but similar to the IVF counterparts $(P>0.05)$.

\section{Effects of cytoplasmic volume on embryonic genome activation of buffalo HMC embryos}

To further understand how the mechanism of increasing recipient cytoplasmic volume enhanced the developmental potential of the HMC embryos, both the EGA marker genes (eIF1A and U2AF) in IVF and HMC embryos at the 2-cell, 4-cell, 8-cell and blastocyst stages were analyzed. The expression of $e I F 1 A$ in the HMC embryos derived from $\sim 225 \%$ cytoplasm was significantly elevated at the 4 -cell and 8 -cell stages $(P<0.05)$ compared with that derived from $\sim 75 \%$ cytoplasm (Fig. $4 \mathrm{a})$. However, no significant differences were noted in the 2-cell or blastocyst stages $(P>0.05)$. As shown in Fig. $4 \mathrm{~b}$, the expression of $U 2 A F$ in the HMC embryos derived from $\sim 225 \%$ cytoplasm at the 8 -cell stage was increased when compared to that derived from $\sim 75 \%$ cytoplasm and $\sim 150 \%$ cytoplasm $(P<0.05)$. 
a

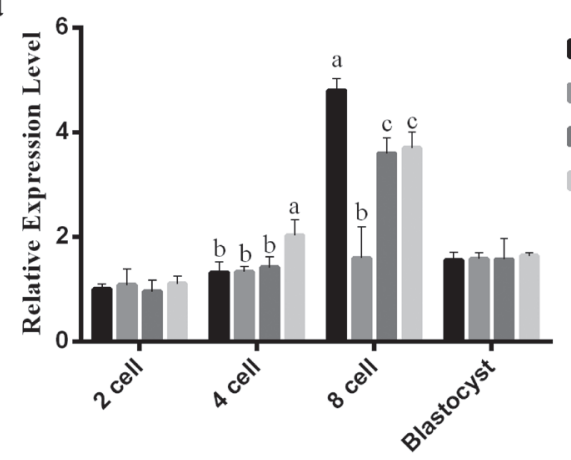

b

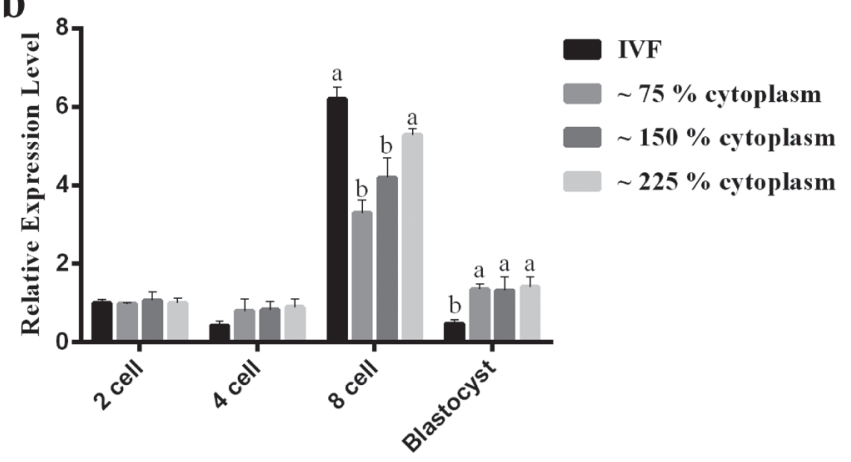

Fig. 4. Relative expression levels of EGA marker genes in embryos derived from IVF, $\sim 75 \%$ cytoplasm, $\sim 150 \%$ cytoplasm or $\sim 225 \%$ cytoplasm HMC embryos. (a) Fold change of $e I F 1 A$ and (b) fold change of $U 2 A F$. Each bar represents the relative fold change between the different embryos. Data shown in the figure are from three replicates $(\mathrm{n}=3)$ and values are presented as mean $\pm \mathrm{SEM}$. Values with different superscripts $(\mathrm{a}, \mathrm{b})$ within groups are significantly different $(P<0.05)$.

Table 4. Pregnancy and calf birth following transfer of HMC embryos producted by distinct cytoplasmic volume

\begin{tabular}{lcccc}
\hline \multicolumn{1}{c}{ Methods } & $\begin{array}{c}\text { Embryos } \\
\text { transferred }\end{array}$ & Recipients & $\begin{array}{c}\text { No. pregnant } \\
\text { recipients day } 60(\%)\end{array}$ & $\begin{array}{c}\text { No. embryos } \\
\text { developed to term (\%) }\end{array}$ \\
\hline HMC embryos with $\sim 75 \%$ cytoplasm & 12 & 6 & 0 & 0 \\
HMC embryos with $\sim 225 \%$ cytoplasm & 19 & 7 & $2(28.6 \%)$ & $1(14.3 \%)$ \\
\hline
\end{tabular}

\section{In vivo developmental competence of HMC embryos}

To evaluate the in vivo developmental competence of the HMC embryos reconstructed with $\sim 75 \%$ cytoplasm or $\sim 225 \%$ cytoplasm, blastocysts were transferred non-surgically into seven recipients. The pregnancy status of the recipients was examined by rectal palpation at 60 days after the embryo transfer. Two of the seven recipients were confirmed to be pregnant following the transfer of blastocysts derived from $\sim 225 \%$ cytoplasm, whereas no recipients were pregnant after transfer of blastocysts derived from $\sim 75 \%$ cytoplasm (Table 4). Unfortunately, one recipient died of illness on Day 200 of gestation and the HMC buffalo fetus was lost (Fig. 5). The remaining recipient maintained its pregnancy to term and delivered one health calf (Fig. 6).

\section{DISCUSSION}

The vast majority of data has shown that the larger the cytoplasm that was removed during enucleation, fewer embryonic cells were present at the morula or blastocyst stage, which could weaken the later developmental competence [12]. Previous studies have shown that the more cytoplasm in the reconstructed embryos, the higher the capacity of these embryos to develop further $[4,23,26]$, which was further confirmed by our study. In this study, we found that increasing the recipient cytoplasmic volume resulted in a higher cleavage and blastocyst rate of reconstructed embryos, which was consistent with previous reports [4, 23]. A higher development of bovine HMC embryos was also achieved by the aggregation of reconstructed embryos with hemi-embryos [26], and with the increase of aggregated embryos, the cleavage, blastocyst rate, and total cell number of blastocysts were also increased. Our results showed that the blastocyst rates and total cell number of blastocysts developed from $\sim 150 \%$ cytoplasm or $\sim 225 \%$ cytoplasm were evidently increased compared with those developed from $\sim 75 \%$ cytoplasm. These results confirmed that increasing cytoplasmic volume could enhance the in vitro development of buffalo HMC embryos. However, hemi-cytoplasts with cytoplasmic volume $(\sim 85 \%$ vs. $2 \times 50 \%)$ showed no effect on the fusion rates after embryo reconstruction in goats [24]. In mice, embryonic aggregation did not improve the cloned embryo development to the blastocyst stage, but it increased the cell density in blastocysts and promoted eight-fold higher in vivo development than the controls [3]. This discrepancy might be attributed to the species specificity; the mechanism involved in this phenomenon still need to be further investigated.

The early events in the nuclear reprogramming process during SCNT consist of the remodeling of the donor nucleus. Several significant morphological changes, such as NEBD and PCC, occur in the donor nucleus after being transferred into recipient cytoplasts. Abnormal nuclear remodeling was frequently observed after SCNT in association with low developmental efficiency. Previous studies suggested that complete reprogramming only occurred after remodeling of the donor nucleus [8], the PCC of the donor nucleus is important for subsequent embryonic development [7]. In mice [43] and pigs [13], a higher in vitro development rate was obtained by inducing PCC, suggesting that PCC might promote effective nuclear reprogramming of the donor cell and enhance the developmental competence of SCNT embryos. It has been reported that modulated oocyte meiotic maturation by treating oocytes or reconstructed embryos with MG132 could induce the PCC of donor cells and promote the pronucleus formation of SCNT embryos $[16,48]$. Similarly, TSA treatment also caused an increase of PCC in 1-cell SCNT embryos that correlated with 


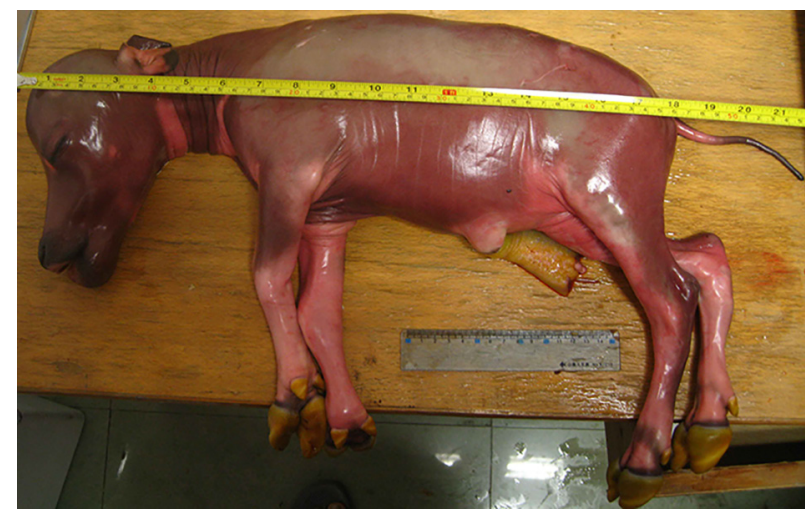

Fig. 5. One HMC buffalo fetus was lost on Day 200 of gestation because the surrogate mother died of illness.

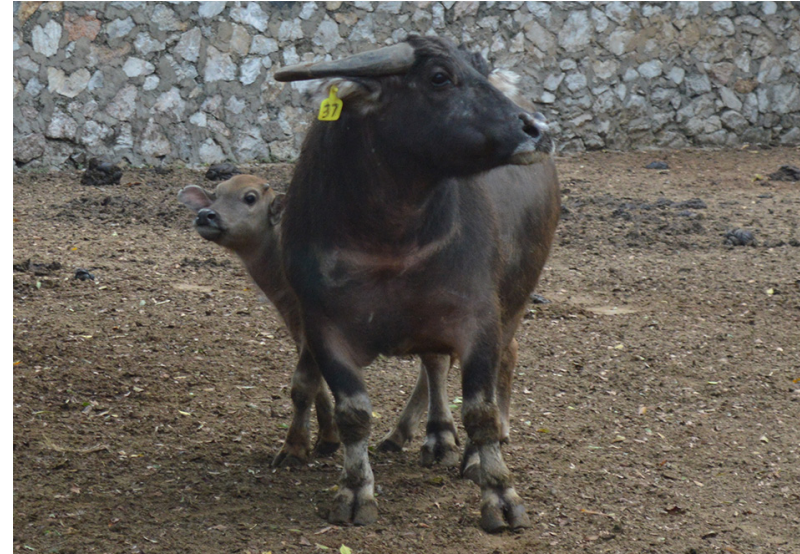

Fig. 6. Eight-month-old HMC buffalo calf (left) and her surrogate mother (right).

the improved rates of embryonic development at subsequent stages $[6,19]$. These reports indicated that the early morphological changes of donor nucleus were closely related to the successful reprogramming. In this study, with the increase of recipient cytoplasmic volume, $100 \%$ of the HMC embryos derived from $225 \%$ cytoplasm experienced NEBD and chromosomes condensed into PCC within $1.5 \mathrm{hr}$ of injection into enucleated oocytes. Moreover, the proportions of NEBD and PCC were significantly higher than that derived from $\sim 75 \%$ cytoplasm. Meanwhile, all of the HMC embryos with $\sim 150 \%$ cytoplasm also completed NEBD and PCC after $3 \mathrm{hr}$ of injection into enucleated oocytes. The different time points of completing nucleus remodeling may be the reason for resulting significantly higher cleavage rate in the $\sim 225 \%$ cytoplasm group than that of the other two groups. Our results indicated that increasing recipient cytoplasmic volume promotes nucleus remodeling, which is beneficial to subsequent embryonic developmental potential.

Global epigenetic reprogramming has been reported as a major process that takes place following SCNT for normal development and successful cloning [47]. Many studies also found that the abnormal modification of histone acetylation and DNA methylation in donor cells might result in the failure of SCNT embryo development [51]. Methylation of cytosines in the mammalian genome represents a key epigenetic modification and global DNA demethylation is important for setting up pluripotent states in early embryos [45]. Currently, the accumulated data have shown that DNA methyltransferase activity was inhibited by chemical inhibitor treatment $[20,30]$ or reduced the DNA methyltransferase-related gene expression by RNA interference [28], which could induce a higher developmental competence of cloned embryos, indicating that the global change of the DNA methylation level is tightly correlated with normal embryonic development. Therefore, we analyzed the DNA methylation level of buffalo HMC embryos derived from different cytoplasmic volumes and found that increasing the recipient cytoplasmic volume resulted in a decrease of global DNA methylation. Conversely, decreasing the recipient cytoplasmic volume significantly elevated the methylation level of HMC embryos from the 2-cell to the 4-cell stages. Our results indicated that increasing the cytoplasm volume promotes the reprogramming of DNA methylation in the donor nucleus and that contributes to the enhancement of the subsequent development of cloned embryo.

EGA is the first major step toward the successful initiation of preimplantation embryonic development, which culminates in the formation of implantation-competent embryos [41]. Previous studies have found that EGA occurs in a species-specific manner: at the 2-cell stage in mice [18]; at the 8-cell to 16-cell stage in cattle [10], and the major EGA takes place between the 4-cell and 8-cell stages, with a minor activation phase between the 2-cell and 4-cell stages in buffalo [41]. The expression of EGA marker genes ( $e I F 1 A$ and $U 2 A F)$ in HMC with different amounts of cytoplasm and IVF embryos were analyzed to document the embryonic transcription initiation events. We found that the expression of eIF $1 A$ in HMC embryos derived from $\sim 225 \%$ cytoplasm at the 4-cell and 8-cell stages was higher than in the $\sim 75 \%$ cytoplasm group. The expression profile of $U 2 A F$ in the HMC embryos derived from $\sim 225 \%$ cytoplasm was increased remarkably at the 8-cell stage compared with that of the $\sim 75 \%$ cytoplasm and $\sim 150 \%$ cytoplasm embryos. Our results partially confirmed that increasing the cytoplasmic volume benefits the onset of EGA.

A large-scale trial of HMC embryo transfer found that the pregnancy rate of HMC embryo transfers was significantly higher than those of fresh IVF or NT embryo transfers, but the overall outcome of cloned offspring did not differ [34]. The removal of the zona pellucida was considered to be the reason for the higher pregnancy rates following embryo transfer [34]. In our case, the pregnancy rate of the HMC embryos derived from $\sim 225 \%$ cytoplasm was higher than those derived from $\sim 75 \%$ cytoplasm. However, one HMC buffalo fetus was lost on Day 200 of gestation because the recipient was ill and died. Moreover, the embryo transfer data are too small to draw a reasonable conclusion. Therefore, the embryos reconstructed with $\sim 150 \%$ cytoplasm or $\sim 225 \%$ cytoplasm have increased cell density in blastocysts, but whether it results in improved embryo developmental potential or survival of the fetus still needs to be determined.

In summary, the cytoplasmic volume of recipient oocytes affects the processes of donor nucleus reprogramming and EGA, and then the related developmental competence of buffalo HMC embryos. However, further studies should be performed to elucidate the mechanism of cytoplasmic increase on full-term development of buffalo SCNT embryos. 
COMPETING INTERESTS. The authors declare that they do not have any competing financial interests.

ACKNOWLEDGMENTS. This work was supported by grants from China High Technology Development Program (2011AA100607), China Transgenic Project (2011ZX08007-003), the China Natural Science Foundation (31560633) and Guangxi Science Foundation (2012GXNSFFA060004).

\section{REFERENCE}

1. Akshey, Y. S., Malakar, D., De, A. K., Jena, M. K., Garg, S., Dutta, R., Pawar, S. K. and Mukesh, M. 2010. Hand-made cloned goat (Capra hircus) embryos - a comparison of different donor cells and culture systems. Cell. Reprogram. 12: 581-588. [Medline] [CrossRef]

2. Bogacki, M., Wasielak, M., Kitewska, A., Bogacka, I. and Jalali, B. M. 2014. The effect of hormonal estrus induction on maternal effect and apoptosis-related genes expression in porcine cumulus-oocyte complexes. Reprod. Biol. Endocrinol. 12: 32. [Medline] [CrossRef]

3. Boiani, M., Eckardt, S., Leu, N. A., Schöler, H. R. and McLaughlin, K. J. 2003. Pluripotency deficit in clones overcome by clone-clone aggregation: epigenetic complementation? EMBO J. 22: 5304-5312. [Medline] [CrossRef]

4. Bowles, E. J., Tecirlioglu, R. T., French, A. J., Holland, M. K. and St John, J. C. 2008. Mitochondrial DNA transmission and transcription after somatic cell fusion to one or more cytoplasts. Stem Cells 26: 775-782. [Medline] [CrossRef]

5. Bui, H. T., Kwon, D. N., Kang, M. H., Oh, M. H., Park, M. R., Park, W. J., Paik, S. S., Van Thuan, N. and Kim, J. H. 2012. Epigenetic reprogramming in somatic cells induced by extract from germinal vesicle stage pig oocytes. Development 139: 4330-4340. [Medline] [CrossRef]

6. Bui, H. T., Wakayama, S., Kishigami, S., Park, K. K., Kim, J. H., Thuan, N. V. and Wakayama, T. 2010. Effect of trichostatin A on chromatin remodeling, histone modifications, DNA replication, and transcriptional activity in cloned mouse embryos. Biol. Reprod. 83: 454-463. [Medline] [CrossRef]

7. Cheong, H. T., Takahashi, Y. and Kanagawa, H. 1994. Relationship between nuclear remodeling and subsequent development of mouse embryonic nuclei transferred to enucleated oocytes. Mol. Reprod. Dev. 37: 138-145. [Medline] [CrossRef]

8. Collas, P. and Robl, J. M. 1991. Relationship between nuclear remodeling and development in nuclear transplant rabbit embryos. Biol. Reprod. 45: 455-465. [Medline] [CrossRef]

9. Du, Y., Kragh, P. M., Zhang, Y., Li, J., Schmidt, M., Bøgh, I. B., Zhang, X., Purup, S., Jørgensen, A. L., Pedersen, A. M., Villemoes, K., Yang, H., Bolund, L. and Vajta, G. 2007. Piglets born from handmade cloning, an innovative cloning method without micromanipulation. Theriogenology 68 : 1104-1110. [Medline] [CrossRef]

10. Frei, R. E., Schultz, G. A. and Church, R. B. 1989. Qualitative and quantitative changes in protein synthesis occur at the 8-16-cell stage of embryogenesis in the cow. J. Reprod. Fertil. 86: 637-641. [Medline] [CrossRef]

11. George, A., Sharma, R., Singh, K. P., Panda, S. K., Singla, S. K., Palta, P., Manik, R. and Chauhan, M. S. 2011. Production of cloned and transgenic embryos using buffalo (Bubalus bubalis) embryonic stem cell-like cells isolated from in vitro fertilized and cloned blastocysts. Cell. Reprogram. 13: 263-272. [Medline] [CrossRef]

12. Hua, S., Zhang, H., Su, J. M., Zhang, T., Quan, F. S., Liu, J., Wang, Y. S. and Zhang, Y. 2011. Effects of the removal of cytoplasm on the development of early cloned bovine embryos. Anim. Reprod. Sci. 126: 37-44. [Medline] [CrossRef]

13. Kawahara, M., Wakai, T., Yamanaka, K., Kobayashi, J., Sugimura, S., Shimizu, T., Matsumoto, H., Kim, J. H., Sasada, H. and Sato, E. 2005. Caffeine promotes premature chromosome condensation formation and in vitro development in porcine reconstructed embryos via a high level of maturation promoting factor activity during nuclear transfer. Reproduction 130: 351-357. [Medline] [CrossRef]

14. Lagutina, I., Lazzari, G., Duchi, R., Colleoni, S., Ponderato, N., Turini, P., Crotti, G. and Galli, C. 2005. Somatic cell nuclear transfer in horses: effect of oocyte morphology, embryo reconstruction method and donor cell type. Reproduction 130: 559-567. [Medline] [CrossRef]

15. Lanza, R. P., Cibelli, J. B., Blackwell, C., Cristofalo, V. J., Francis, M. K., Baerlocher, G. M., Mak, J., Schertzer, M., Chavez, E. A., Sawyer, N., Lansdorp, P. M. and West, M. D. 2000. Extension of cell life-span and telomere length in animals cloned from senescent somatic cells. Science 288: 665-669. [Medline] [CrossRef]

16. Le Bourhis, D., Beaujean, N., Ruffini, S., Vignon, X. and Gall, L. 2010. Nuclear remodeling in bovine somatic cell nuclear transfer embryos using MG132-treated recipient oocytes. Cell. Reprogram. 12: 729-738. [Medline] [CrossRef]

17. Li, S., Kang, J. D., Jin, J. X., Hong, Y., Zhu, H. Y., Jin, L., Gao, Q. S., Yan, C. G., Cui, C. D., Li, W. X. and Yin, X. J. 2014. Effect of demecolcineassisted enucleation on the MPF level and cyclin B1 distribution in porcine oocytes. PLoS One 9: e91483. [Medline] [CrossRef]

18. Ma, J., Svoboda, P., Schultz, R. M. and Stein, P. 2001. Regulation of zygotic gene activation in the preimplantation mouse embryo: global activation and repression of gene expression. Biol. Reprod. 64: 1713-1721. [Medline] [CrossRef]

19. Maalouf, W. E., Liu, Z., Brochard, V., Renard, J. P., Debey, P., Beaujean, N. and Zink, D. 2009. Trichostatin A treatment of cloned mouse embryos improves constitutive heterochromatin remodeling as well as developmental potential to term. BMC Dev. Biol. 9: 11. [Medline] [CrossRef]

20. Mao, J., Zhao, M. T., Whitworth, K. M., Spate, L. D., Walters, E. M., O’Gorman, C., Lee, K., Samuel, M. S., Murphy, C. N., Wells, K., Rivera, R. M. and Prather, R. S. 2015. Oxamflatin treatment enhances cloned porcine embryo development and nuclear reprogramming. Cell. Reprogram. 17: 28-40. [Medline] [CrossRef]

21. Ng, R. K. and Gurdon, J. B. 2005. Maintenance of epigenetic memory in cloned embryos. Cell Cycle 4: 760-763. [Medline] [CrossRef]

22. Oback, B., Wiersema, A. T., Gaynor, P., Laible, G., Tucker, F. C., Oliver, J. E., Miller, A. L., Troskie, H. E., Wilson, K. L., Forsyth, J. T., Berg, M. C., Cockrem, K., McMillan, V., Tervit, H. R. and Wells, D. N. 2003. Cloned cattle derived from a novel zona-free embryo reconstruction system. Cloning Stem Cells 5: 3-12. [Medline] [CrossRef]

23. Panda, S. K., George, A., Saha, A. P., Sharma, R., Manik, R. S., Chauhan, M. S., Palta, P. and Singla, S. K. 2011. Effect of cytoplasmic volume on developmental competence of buffalo (Bubalus bubalis) embryos produced through hand-made cloning. Cell. Reprogram. 13: 257-262. [Medline] [CrossRef]

24. Pereira, A. F., Feltrin, C., Almeida, K. C., Carneiro, I. S., Avelar, S. R. G., Neto, A. S., Sousa, F. C., Melo, C. H. S., Moura, R. R., Teixeira, D. I. A., Bertolini, L. R., Freitas, V. J. F. and Bertolini, M. 2013. Analysis of factors contributing to the efficiency of the in vitro production of transgenic goat embryos (Capra hircus) by handmade cloning (HMC). Small Rumin. Res. 109: 163-172. [CrossRef]

25. Rathbone, A. J., Fisher, P. A., Lee, J. H., Craigon, J. and Campbell, K. H. 2010. Reprogramming of ovine somatic cells with Xenopus laevis oocyte extract prior to SCNT improves live birth rate. Cell. Reprogram. 12: 609-616. [Medline] [CrossRef]

26. Ribeiro, E. S., Gerger, R. P., Ohlweiler, L. U., Ortigari, I. Jr., Mezzalira, J. C., Forell, F., Bertolini, L. R., Rodrigues, J. L., Ambrósio, C. E., Miglino, 
M. A., Mezzalira, A. and Bertolini, M. 2009. Developmental potential of bovine hand-made clone embryos reconstructed by aggregation or fusion with distinct cytoplasmic volumes. Cloning Stem Cells 11: 377-386. [Medline] [CrossRef]

27. Saha, A., Panda, S. K., Chauhan, M. S., Manik, R. S., Palta, P. and Singla, S. K. 2013. Birth of cloned calves from vitrified-warmed zona-free buffalo (Bubalus bubalis) embryos produced by hand-made cloning. Reprod. Fertil. Dev. 25: 860-865. [Medline] [CrossRef]

28. Selokar, N. L., Saini, M., Agrawal, H., Palta, P., Chauhan, M. S., Manik, R. and Singla, S. K. 2015. Downregulation of DNA methyltransferase 1 in zona-free cloned buffalo (Bubalus bubalis) embryos by small interefering RNA improves in vitro development but does not alter DNA methylation level. Cell. Reprogram. 17: 89-94. [Medline] [CrossRef]

29. Shi, D., Lu, F., Wei, Y., Cui, K., Yang, S., Wei, J. and Liu, Q. 2007. Buffalos (Bubalus bubalis) cloned by nuclear transfer of somatic cells. Biol. Reprod. 77: 285-291. [Medline] [CrossRef]

30. Sun, H., Lu, F., Zhu, P., Liu, X., Tian, M., Luo, C., Ruan, Q., Ruan, Z., Liu, Q., Jiang, J., Wei, Y. and Shi, D. 2015. Effects of scriptaid on the histone acetylation, dna methylation and development of buffalo somatic cell nuclear transfer embryos. Cell. Reprogram. 17: 404-414. [Medline] [CrossRef]

31. Tang, S., Wang, Y., Zhang, D., Gao, Y., Ma, Y., Yin, B., Sun, J., Liu, J. and Zhang, Y. 2009. Reprogramming donor cells with oocyte extracts improves in vitro development of nuclear transfer embryos. Anim. Reprod. Sci. 115: 1-9. [Medline] [CrossRef]

32. Tani, T., Shimada, H., Kato, Y. and Tsunoda, Y. 2006. Demecolcine-assisted enucleation for bovine cloning. Cloning Stem Cells 8: 61-66. [Medline] [CrossRef]

33. Tatham, B. G., Dowsing, A. T. and Trounson, A. O. 1995. Enucleation by centrifugation of in vitro-matured bovine oocytes for use in nuclear transfer. Biol. Reprod. 53: 1088-1094. [Medline] [CrossRef]

34. Tecirlioglu, R. T., Cooney, M. A., Lewis, I. M., Korfiatis, N. A., Hodgson, R., Ruddock, N. T., Vajta, G., Downie, S., Trounson, A. O., Holland, M. K. and French, A. J. 2005. Comparison of two approaches to nuclear transfer in the bovine: hand-made cloning with modifications and the conventional nuclear transfer technique. Reprod. Fertil. Dev. 17: 573-585. [Medline] [CrossRef]

35. Vajta, G. 2007. Handmade cloning: the future way of nuclear transfer? Trends Biotechnol. 25: 250-253. [Medline] [CrossRef]

36. Vajta, G., Bartels, P., Joubert, J., de la Rey, M., Treadwell, R. and Callesen, H. 2004. Production of a healthy calf by somatic cell nuclear transfer without micromanipulators and carbon dioxide incubators using the Handmade Cloning (HMC) and the Submarine Incubation System (SIS). Theriogenology 62: 1465-1472. [Medline] [CrossRef]

37. Vajta, G., Kragh, P. M., Mtango, N. R. and Callesen, H. 2005. Hand-made cloning approach: potentials and limitations. Reprod. Fertil. Dev. 17: 97-112. [Medline] [CrossRef]

38. Vajta, G., Lewis, I. M., Hyttel, P., Thouas, G. A. and Trounson, A. O. 2001. Somatic cell cloning without micromanipulators. Cloning 3: 89-95. [Medline] [CrossRef]

39. Vajta, G., Lewis, I. M., Trounson, A. O., Purup, S., Maddox-Hyttel, P., Schmidt, M., Pedersen, H. G., Greve, T. and Callesen, H. 2003. Handmade somatic cell cloning in cattle: analysis of factors contributing to high efficiency in vitro. Biol. Reprod. 68: 571-578. [Medline] [CrossRef]

40. Vajta, G., Peura, T. T., Holm, P., Páldi, A., Greve, T., Trounson, A. O. and Callesen, H. 2000. New method for culture of zona-included or zona-free embryos: the Well of the Well (WOW) system. Mol. Reprod. Dev. 55: 256-264. [Medline] [CrossRef]

41. Verma, A., Kumar, P., Rajput, S., Roy, B., De, S. and Datta, T. K. 2012. Embryonic genome activation events in buffalo (Bubalus bubalis) preimplantation embryos. Mol. Reprod. Dev. 79: 321-328. [Medline] [CrossRef]

42. Verma, G., Arora, J. S., Sethi, R. S., Mukhopadhyay, C. S. and Verma, R. 2015. Handmade cloning: recent advances, potential and pitfalls. J. Anim. Sci. Biotechnol. 6: 43. [Medline] [CrossRef]

43. Wakayama, T., Perry, A. C., Zuccotti, M., Johnson, K. R. and Yanagimachi, R. 1998. Full-term development of mice from enucleated oocytes injected with cumulus cell nuclei. Nature 394: 369-374. [Medline] [CrossRef]

44. Westhusin, M. E., Collas, P., Marek, D., Sullivan, E., Stepp, P., Pryor, J. and Barnes, F. 1996. Reducing the amount of cytoplasm available for early embryonic development decreases the quality but not quantity of embryos produced by in vitro fertilization and nuclear transplantation. Theriogenology 46: 243-252. [Medline] [CrossRef]

45. Wu, H. and Zhang, Y. 2014. Reversing DNA methylation: mechanisms, genomics, and biological functions. Cell 156: 45-68. [Medline] [CrossRef]

46. Yang, C. Y., Pang, C. Y., Yang, B. Z., Li, R. C., Lu, Y. Q. and Liang, X. W. 2012. Optimization of cryopreservation of buffalo (Bubalus bubalis) blastocysts produced by in vitro fertilization and somatic cell nuclear transfer. Theriogenology 78: 1437-1445. [Medline] [CrossRef]

47. Yang, J., Yang, S., Beaujean, N., Niu, Y., He, X., Xie, Y., Tang, X., Wang, L., Zhou, Q. and Ji, W. 2007. Epigenetic marks in cloned rhesus monkey embryos: comparison with counterparts produced in vitro. Biol. Reprod. 76: 36-42. [Medline] [CrossRef]

48. You, J., Lee, J., Kim, J., Park, J. and Lee, E. 2010. Post-fusion treatment with MG132 increases transcription factor expression in somatic cell nuclear transfer embryos in pigs. Mol. Reprod. Dev. 77: 149-157. [Medline]

49. Zakhartchenko, V., Stojkovic, M., Brem, G. and Wolf, E. 1997. Karyoplast-cytoplast volume ratio in bovine nuclear transfer embryos: effect on developmental potential. Mol. Reprod. Dev. 48: 332-338. [Medline] [CrossRef]

50. Zhang, P., Liu, P., Dou, H., Chen, L., Chen, L., Lin, L., Tan, P., Vajta, G., Gao, J., Du, Y. and Ma, R. Z. 2013. Handmade cloned transgenic sheep rich in omega-3 Fatty acids. PLoS One 8: e55941. [Medline] [CrossRef]

51. Zhang, S., Chen, X., Wang, F., An, X., Tang, B., Zhang, X., Sun, L. and Li, Z. 2016. Aberrant DNA methylation reprogramming in bovine SCNT preimplantation embryos. Sci. Rep. 6: 30345. [Medline] [CrossRef] 